\title{
PERANAN GURU PENDIDIKAN AGAMA ISLAM DALAM MEMBINA AKHLAK PESERTA DIDIK
}

\author{
Nurlela, Eri Purwanti \\ STMIK dan STIT Pringsewu \\ E-mail: nlela8426@gmail.com, eripurwantimpd@gmail.com HP. 085379761769
}

\begin{abstract}
This research examines the role of teachers of Islamic education in fostering morals learners in vocational Teknika Graphic Kartika Gadingrejo Gadingrejo District of the Academic Year 2017/2018. The data is processed through three stages: data reduction, data display, and verification of data and the conclusions drawn and analyzed qualitatively. Used an interdisciplinary approach, namely the theological-normative approach, educational approach, psychological approach, and sociological approach. The result shows that there are four roles that teachers as teachers, teacher educators, teachers as mentors and teachers as coaches conducted by PAI teacher in SMK Teknika Graphic Kartika Gadingrejo directed to fostering the morals of students, namely to instill and awaken religious beliefs, teach proper etiquette in the family environment.
\end{abstract}

Keywords: Islamic Education Teacher, Fostering, Morals.

\begin{abstract}
Abstrak: Penelitian ini mengkaji peranan guru Pendidikan Agama Islam dalam membina akhlak peserta didik di SMK Teknika Grafika Kartika Gadingrejo Kecamatan Gadingrejo Tahun Pelajaran 2017/2018. Data diolah melalui tiga tahap yaitu reduksi data, display data, dan verifikasi data, lalu ditarik kesimpulan dan dianalisis secara kualitatif. Digunakan pendekatan interdisipliner, yaitu pendekatan teologis-normatif, pendekatan paedagogis, pendekatan psikologis, dan pendekatan sosiologis. Hasilnya menunjukkan terdapat 4 peranan yaitu guru sebagai pengajar, guru sebagai pendidik, guru sebagai pembimbing, dan guru sebagai pelatih yang dilakukan oleh guru PAI di SMK Teknika Grafika Kartika Gadingrejo yang mengarah pada upaya pembinaan akhlak peserta didik, yaitu menanamkan dan membangkitkan keyakinan beragama, menanamkan etika pergaulan baik dalam lingkungan keluarga, lingkungan masyarakat, dan lingkungan sekolah serta menanamkan kebiasan yang baik berupa kedisiplinan, tanggung jawab, melakukan hubungan sosial dan melakukan ibadah ritual..
\end{abstract}

Kata kunci: Guru Pendidikan Agama Islam, Membina, Akhlak. 


\section{A. PENDAHULUAN}

Pada saat menghadapi arus globalisasi, guru Pendidikan Agama Islam (PAI) memegang peranan dominan dalam pembinaan akhlak siswa. Berhasil atau tidaknya suatu lembaga pendidikan dalam mencapai tujuan keberhasilan peserta didiknya dalam pembinaan akhlak, tergantung pada kemampuan guru dalam menjalankan tugas-tugas yang dibebankan kepadanya sesuai kompetensi yang dimiliki dalam hal ilmu mendidik, dan khususnya dalam pembinaan akhlak bagi peserta $\operatorname{didik}[1]$, [2].

Pendidikan Agama Islam sebagai suatu disiplin ilmu, mempunyai karakteristik dan tujuan yang berbeda dari disiplin ilmu yang lain, bahkan sangat mungkin berbeda sesuai dengan orientasi dari masing-masing lembaga yang menyelenggarakannya. Pusat Kurikulum Depdiknas mengemukakan bahwa Pendidikan Agama Islam di Indonesia bertujuan untuk menumbuhkan dan meningkatkan keimanan, peserta didik melalui pemberian dan pemupukan pengetahuan, penghayatan, pengamalan serta pengalaman peserta didik tentang agama Islam sehingga menjadi manusia muslim yang terus berkembang dalam hal keimanan, ketaqwaannya kepada Allah SWT, serta berakhlak mulia dalam kehidupan pribadi, bermasyarakat, berbangsa dan bernegara[3], [4].

Berdasarkan observasi penulis, terhadap Guru di SMK Teknika Grafika Kartika Gadingrejo Kecamatan Gadingrejo, dalam kegiatan belajar mengajar memberikan sikap keteladanan dan menjalankan peran sebagai seorang guru terhadap peserta didiknya. Namun akhlak siswa di SMK Teknik Grafika Kartika Gadingrejosebagian masih belum dianggap baik, karena masih ditemukan siswa membuang sampah sembarangan, cara berpakaian tidak rapih dan sopan, cara berbicara dengan guru dan karyawan kurang sopan, masih ditemukan siswa makan dan minum sambil berjalan, siswa laki-laki memakai gelang dan kalung, ribut dalam ruangan kelas saat guru tidak ada, mengolok-olok teman, pada waktu upacara main-main, susah mengikuti kegiatan keagamaan di sekolah, dll.
Pentingnya permasalahan akhlak bagi peserta didik di SMK Teknika Grafika Kartika Gadingrejo merupakan bagian dari tanggung jawab guru, dimana seorang guru dituntut untuk lebih serius, optimal dan professional dalam pembinaan akhlak siswa di sekolah., dan diharapkan siswa mampu memahami, menghayati dan mengamalkan nilai-nilai ajaran agama Islam dalam kehidupan sehari-hari. Berdasarkan asumsi di atas, maka penulis tertarik untuk melakukan penelitian dengan judul "Peranan Guru Pendidikan Agama Islam (PAI) dalam Membina Akhlak Peserta Didik di SMK Teknika Grafika Kartika Gadingrejo Kecamatan Gadingrejo.

\section{B. METODEPENELITIAN}

Penelitian ini merupakan penelitian kualitatif. Dalam penelitian kualitatif data yang dikumpulkan bukan angka-angka, akan tetapi berupa kata-kata atau gambaran. Data yang dimaksud berasal dari wawancara, catatan lapangan, observasi, dokumen pribadi dan dokumen-dokumen lainnya[5], [6]. Sesuai dengan tema yang peneliti bahas, penelitian ini menggunakan jenis penelitian lapangan (Field Research), dimana penelitian SMK Teknika Grafika Kartika Gadingrejo Kecamatan Gadingrejo (obyek penelitian) untuk mendapatkan data-data yang diperlukan. Peneliti mengadakan pengamatan tentang sesuatu fenomenon dalam suatu keadaan alamiah. Peneliti lapangan biasanya membuat catatan lapangan secara ekstensif yang kemudian dibuatkan kode dan dianalisis dalam berbagai cara.Data diolah melalui tiga tahap yaitu reduksi data, display data, dan verifikasi data, lalu ditarik kesimpulan dan dianalisis secara kualitatif. Digunakan pendekatan interdisipliner, yaitu pendekatan teologis-normatif, pendekatan paedagogis, pendekatan psikologis, dan pendekatan sosiologis[7]

Lokasi penelitian ini dilaksanakan di SMK Teknika Grafika Kartika Gadingrejo Kecamatan gadingrejo Kabupaten Pringsewu. Pemilihan lokasi didasarkan pada pertimbangan bahwa tingkat intensitas peranan guru PAI di sekolah ini cukup tinggi dan beragam. 


\section{HASIL DAN PEMBAHASAN}

1. Peranan Guru Pendidikan Agama Islam (PAI) Dalam Membina Akhlak Peserta Didik Data Hasil Ceklist Kemampuan Berdiskusi Dalam Pembelajaran Model Debate (X)

Berangkat dari konsep operasional, pendidikan Islam adalah transformasi ilmu pengetahuan dan internalisasi nilai-nilai Islam dalam rangka mengembangkan fitrah dan kemampuan dasar yang dimiliki peserta didik, guna mencapai keseimbangan dan kesetaraan dalam berbagai aspek kehidupan, maka pendidik (guru) mempunyai peran yang sangat penting dalam pendidikan Islam.

Sekolah dapat dijadikan kondisi yang memungkinkan berkembangnya atau terhambatnya suatu proses penyesuaian diri dan perkembangan akhlak peserta didik. Pada umumnya, sekolah dipandang sebagai media yang sangat berguna untuk mempengaruhi kehidupan dan perkembangan intelektual, sosial, nilai-nilai, sikap, dan akhlak peserta didik. Apalagi bagi peserta didik, seringkali figur guru umum dan guru Pendidikan Agama Islam sangat disegani, dikagumi, dan dituruti. Tidak jarang peserta didik lebih mendengarkan dan menuruti apa yang dikatakan oleh guru atau guru agama daripada orang tuanya. Oleh sebab itu, proses sosialisasi yang dilakukan melalui iklim kehidupan sekolah yang diciptakan oleh guru atau guru Pendidikan Agama Islam dalam interkasi pendidikannya sangat berpengaruh terhadap perkembangan akhlak pada peserta didik. Untuk itu, guru Pendidikan Agama Islam melakukan beberapa peranan agar peserta didik dapat melakukan perkembangan akhlak yang baik atau terpuji (akhlakul karimah).

Lebih lanjut, berdasarkan wawancara dengan salah satu guru Masrurdi SMK Teknika Grafika Kartika
Gadingrejo, menjelaskan bahwa dalam pelaksanaan peranannya guru Pendidikan Agama Islam (PAI) dalam membina akhlak pada peserta didik di SMK Teknika Grafika Kartika gadingrejo dilakukan melalui empat peranan guru PAI, yaitu: 1) guru sebagai pengajar; 2) guru sebagai pendidik; 3) guru sebagai pembimbing; dan guru sebagai pelatih atau pembina.

2. Faktor Pendukung dan Penghambat Peranan Guru PAI dalam Mdembina Akhlak Peserta Didik di SMK Teknika Gadingrejo

Dalam proses pelaksanannya, peranan guru PAI dalam membina akhlak peserta didik di SMK Teknika Grafika Kartika Gadingrejo, terdapat hal-hal yang mendukung dan juga menjadi penghambat kegiatan tersebut. Berdasarkan observasi dan wawancara, dapatlah penulis identifikasi faktor pendukung dan penghambat tersebut.

a.Faktor Pendukung

Adapun hal-hal yang menjadi faktor pendukung dalam proses pembinaan akhlak yang dilakukan guru PAI di SMK Teknika Grafika Kartika Gadingrejo, antara lain:

1) Kurikulum

2) Tenaga guru dan warga sekolah

3) Peran serta orang tua.

b. Faktor Penghambat

Selain faktor pendukung, ada pula faktor penghambat dalam pembinaan akhlak peserta didik di SMK Teknika Grafika Kartikagadingrejo yang penulis identifikasi sebagai berikut.

1) Faktor internal berupa pembinaan akhlak pada peserta didik hanya dilakukan sebatas di sekolah saja dan belum adanya tindak lanjutnya.

2) Adapun faktor eksternal meliputi lingkungan keluarga, lingkungan masyarakat, dan arus globalisasi modern[8], [9].

Berangkat dari hasil wawancara dengan guru PAI di SMK Teknika Grafika Kartika Gadingrejo. Ada tiga hal penting 
yang penulis identifikasi untuk kemudian dideskripsikan sebagai bagian dari upaya yang telah dilakukan oleh guru PAI dalam membina akhlak peserta didik, yaitu menanamkan dan membangkitkan keyakinan beragama, menanamkan etika pergaulan, dan menanamkan kebiasaan yang baik.

a. Menanamkan dan membangkitkan keyakinan beragama

Keyakinan terhadap Tuhan Yang Maha Esa adalah hal mutlak pertama dan utama yang perlu diyakinkan oleh guru PAI di SMK Teknika Grafika Kartika Gadingrejo kepada peserta didik. Kondisi peserta didik yang hetrogen dan rawan dengan gesekan teologis menjadi salah satu faktor pentingnya penanaman akidah Islam yang kuat bagi peserta didik di SMK Teknika Grafika Kartika Gadingrejo. Dalam upaya menanamkan keyakinan beragama, guru PAI melakukan hal-hal sebagai berikut.

1. Memberikan pemahaman tentang Akhlak kepada Allah SWT

2. Memberikan pemahaman untuk meneladani akhlak Nabi Muhammad SAW[10].

b. Menanamkan etika pergaulan

Dalam berbagai kesempatan, seperti pada saat pelaksanaan tazkir, PHBI maupun kegiatan lainnya, peserta didik senantiasa diberikan pembinaan dan motivasi agar menjaga pergaulan sesuai dengan nilai-nilai Islam rahmatan li alalamin. Terutama sekali dalam pergaulan dengan non muslim yang menjadi kelompok minoritas di SMK Teknika Grfaika Kartika Gadingrejo. Setiap siswa muslim akan membawa nama baik dan citra Islam yang tenang dan penuh kedamaian.

c. Menanamkan kebiasaan yang baik

Intensitas kegiatan pembelajaran PAI yang cukup tinggi di SMK Teknika Grafika Kartika Gadingrejo, memberikan kesempatan kepada PAI untuk memberikan kebebasan kepada peserta didik melalui pembiasaan. Beberapa nilai akhlak yang ditanamkan melalui pembiasaan ini antara lain[11], [12]:

1. Membiasakan untuk disiplin
Hasil wawancara yang penulis peroleh dari peserta didik berkaitan dengan kehadiran dalam kegiatan pembelajaran menunjukkan kondisi sebagaimana pada tabel berikut ini. Tabel 4.3

Sikap Kehadiran Peserta Didik Setiap Pembelajaran PAI

\begin{tabular}{|c|l|c|c|}
\hline No & $\begin{array}{c}\text { Sikap } \\
\text { kehadiran }\end{array}$ & Frekuensi & $\begin{array}{c}\text { Persentase } \\
(\%)\end{array}$ \\
\hline 1 & Datang & 5 & 10,20 \\
2 & lebih awal & 42 & 85,72 \\
3 & Tepat & 2 & 4,08 \\
& waktu & & \\
& Terlambat & & 100,00 \\
\hline \multicolumn{2}{|c|}{ Jumlah } & 49 & .
\end{tabular}

Yang dimaksud datang lebih awal yaitu peserta didik yang datang sekitar 10 s.d 15 menit sebelum bel pembelajaran dimulai. Adapun yang datang tepat waktu, maksudnya datang sekitar 5 s.d 10 menit sebelum pelajaran berlangsung. Adapun peserta didik yang terlambar datang sekitar 5 s.d 10 menit saat berlangsungnya pembelajaran. Dengan demikian, penulis dapat menyimpulkan bahwa guru PAI SMK Teknika Grafika Kartika Gadingrejo cukup mampu membiasakan peserta didik untuk disiplin dalam kehadiran setiap kegiatan pembelajaran di kelas.

Hal tersebut sesuai dengan hasil wawancara dengan guru PAI yang menyatakan bahwa upaya memotivasi peserta didik untuk hadir dalam pembelajaran di kelas senantiasa dilakukan. Peserta didik diberikan keyakinan tentang pentingnya kehadiran dalam setiap pembelajaran di kelas karena mereka juga mengemban misi dakwah sekolah Unsur kedua dalam upaya pembinaan disiplin adalah sikap peserta didik pada saat berlangsungnya pembelajaran di kelas yang dapat dilihat pada tabel berikut.

Tabel 4.4

Sikap Peserta Didik Saat Berlangsung Pembelajaran PAI di Kelas

\begin{tabular}{|c|c|c|c|}
\hline No & $\begin{array}{c}\text { Sikap saat } \\
\text { Pembelajaran } \\
\text { di Kelas }\end{array}$ & Frekuensi & $\begin{array}{c}\text { Persentase } \\
(\%)\end{array}$ \\
\hline 1 & Mengikuti & 40 & 81,63 \\
\hline
\end{tabular}




\begin{tabular}{|c|c|c|c|}
\hline 2 & dengan tertib & & \\
3 & $\begin{array}{c}\text { Sesekali } \\
\text { berbicara } \\
\text { dengan }\end{array}$ & 0 & 18,37 \\
& $\begin{array}{c}\text { teman } \\
\text { Sering keluar }\end{array}$ & & 00,00 \\
\hline & Jumlah & 49 & 100,00 \\
\hline
\end{tabular}

Tertib yang penulis maksudkan adalahmengikuti PBM dengan tenang dari awal hingga akhir tanpa membuat kegaduhan. Sesekali berbicara dengan teman artinya, sekali-sekali bercakapcakap dengan teman disampingnya tentang hal-hal yang berkaitan dengan materi yang disampaikan. Adapu sering keluar maksudnya meninggalkan ruang kelas untuk keperluan mendesak, misalnya ke toilet.Jadi dapat disimpulkan bahwa umumnya sikap peserta didik pada saat berlangsung proses belajar mengajar (PBM) adalah mengikuti dengan tertib. Hanya beberapa yang sekali-sekali berbicara dengan teman di sampingnya ini pun berkaitan dengan materi yang sedang disampaikan atau dibicarakan oleh guru PAI.

2. Membiasakan untuk bertanggung jawab

Berkaitan dengan penyelesaian tugas sebagai tanggungjawab peserta didik dalam pembelajaran PAI, berdasarkan pada hasil wawancara penulis dengan guru PAI menunjukkan bahwa pada umumnya peserta didik memiliki rasa tanggungjawab yang tinggi untuk melaksanakannya dengan baik. Tabel 4.5

Sikap Peserta Didik Ketika Mendapat Tugas

\begin{tabular}{|c|c|c|c|}
\hline & dalam & BM PAI & \\
\hline No & $\begin{array}{l}\text { Sikap Ketika } \\
\text { Mendapat }\end{array}$ & Frekuensi & $\begin{array}{l}\text { Persentase } \\
(\%)\end{array}$ \\
\hline 1 & $\begin{array}{l}\text { Melaksanakan } \\
\text { dengan } \\
\text { tanggungjawab }\end{array}$ & 45 & 91,84 \\
\hline 2 & $\begin{array}{l}\text { Melaksanakan } \\
\text { tapi tidak } \\
\text { sepenuh hati }\end{array}$ & 4 & 08,16 \\
\hline 3 & $\begin{array}{l}\text { Minta } \\
\text { digantikan } \\
\text { teman lainnya }\end{array}$ & 0 & 00,00 \\
\hline & Jumlah & 49 & 100,00 \\
\hline
\end{tabular}

Berdasarkan tabel tersebut, informasi yang penulis dapatkan yaitu bahwa peserta didik yang diberikan tugas dalam kegiatan PBM PAI, umumnya melaksanakan dengan baik tanggungjawabnya. Sekalipun ada juga yang tidak sepenuh hati, mereka tetap melaksanakan tugasnya dan tidak meminta untuk digantikan oleh teman yang lain

3. Membiasakan untuk melakukan hubungan sosial

Sikap sosial yang ditunjukkan oleh peserta didik muslim di SMK Teknika Grafika Kartika Gadingrejo tentang hubungan peserta didik dengan guru dan dengan teman lainnya tampak dalam tabel berikut.

Tabel 4.6

Hubungan Peserta Didik dengan Guru

\begin{tabular}{|c|c|c|c|}
\hline No & $\begin{array}{c}\text { Hubungan } \\
\text { Peserta Didik } \\
\text { Dengan Guru }\end{array}$ & frekuensi & Persentase (\%) \\
\hline 1 & $\begin{array}{l}\text { Sangat Baik } \\
\text { Baik Sekali }\end{array}$ & 6 & 12,25 \\
\hline 2 & $\begin{array}{c}\text { Baik } \\
\text { Kurang Baik }\end{array}$ & 10 & 20,41 \\
\hline 3 & Buruk & 33 & 67,34 \\
\hline 4 & & $\begin{array}{l}0 \\
0\end{array}$ & $\begin{array}{c}00,00 \\
00,00\end{array}$ \\
\hline & Jumlah & 49 & 100,00 \\
\hline
\end{tabular}

Tidak ditemukan adanya hubungan yang kurang baikapalagi hubungan yang buruk sesama peserta didik. Jika kondisinya demikian, maka akan lebih mudah bagi guru PAI dalam melakukan upaya pembinaan akhlak peserta didik karena suasana yang kondusif sangat menunjang proses tersebut.

Membantu sesama teman yang memerlukan pertolongan merupakan salah satu bentuk sikap sosial yang selalu ditanamkan guru PAI untuk dibiasakan. Pertolongan yang penulis maksudkan adalah dalam makna positif dan konteks akhlak mulia.

Tabel 4.7

Hubungan Sesama Peserta Didik

Sikap Terhadap Teman Yang Butuh Pertolongan

\begin{tabular}{|c|c|c|c|}
\hline $\begin{array}{l}\mathrm{N} \\
\mathrm{O}\end{array}$ & $\begin{array}{c}\text { Sikap } \\
\text { Terhadap } \\
\text { Teman } \\
\text { Yang Butuh } \\
\text { Pertolongan }\end{array}$ & $\begin{array}{c}\text { frekuen } \\
\mathrm{si}\end{array}$ & $\begin{array}{c}\text { Persentas } \\
\text { e }(\%)\end{array}$ \\
\hline 1 & Segera & 40 & 81,63 \\
\hline
\end{tabular}




\begin{tabular}{|c|c|c|c|}
\hline & Menolong & & \\
\hline 2 & $\begin{array}{l}\text { Menunggu } \\
\text { teman }\end{array}$ & 2 & 4,08 \\
\hline 3 & $\begin{array}{l}\text { menolong } \\
\text { dulu }\end{array}$ & 7 & 14,29 \\
\hline 4 & $\begin{array}{l}\text { Menanyaka } \\
\mathrm{n} \\
\text { keperluann }\end{array}$ & 0 & 00,00 \\
\hline 5 & $\begin{array}{l}\text { Tidak } \\
\text { Menolong } \\
\text { Tidak } \\
\text { peduli sama } \\
\text { sekali }\end{array}$ & 0 & 00,00 \\
\hline & Jumlah & 49 & 100,00 \\
\hline
\end{tabular}

Peserta didik di SMK Teknika

Grafika Kartika Gadingrejo memiliki sikap yang peka terhadap bentuk pertolongan, tidak bersikap acuh apalagi tidak menolong. Ini merupakan kebiasan baik yang selalu ditanamkan oleh guru PAI kepada peserta didik agar menjadi bagian dalam hidupnya. Sebagai anggota masyarakat, sikap suka menolong perlu dibiasakan sejak dini.

4. Membiasakan untuk melakukanibadah ritual

Di SMK Teknika Gadingrejo, sekalipun dengan keterbatasan yang ada, guru PAI berupaya untuk membiasakan peserta didik melaksanakan ibadah shalat, khususnya shala zhuhur berjamaah di sekolah. Teknis pelaksanaannya sebagaimana dijelaskan oleh $\mathrm{M}$. Masrur, bahwa ketika masuk waktu zhuhur, khusus peserta didik muslim diberikan dispensasi untuk melaksanakan shalat dzuhur di ruang musholla yang ada di sekolah, hanya saja perlu dilaksanakan secara bergiliran karena keterbatasan kapasitas ruangannya.

\section{KESIMPULAN}

Berdasarkan deskripsi pada beberapa bab sebelumnya dan pengamatan yang penulislakukan di SMK Teknika Grafika Kartika Gadingrejo, dapat dikemukakan beberapa kesimpulan sebagai berikut.
1. Ada empat peranan yang dilakukan guru PAI Islam dalam membina akhlak pada peserta didik, yaitu:

a. Guru sebagai pengajar;

b. Guru sebagai pendidik;

c. Guru sebagai pembimbing;

d. Guru sebagai pelatih.

2. Guru PAI berupaya menanamkan etika pergaulan yang meliputi akhlak dalam lingkungan keluarga, akhlak dalam lingkungan masyarakat dan akhlak dalam lingkungan sekolah. Upaya selanjutnya adalah menanamkan kebiasaan yang baik terutama dalam membiasakan untuk disiplin, bertanggungjawab, melakukan hubungan sosial dan ibadah ritual.

3. Dalam pelaksanaan peranan guru PAI dalam membina akhlak pada peserta didik di SMK Teknika Grafika Kartika Gadingrejo, terdapat faktor pendukung dan penghambat yang penulis identifikasi sebagai berikut.

a. Faktor pendukung yang meliputi kurikulum PAI, tenaga guru dan warga sekolah dan peran serta orang tua.

b. Faktor penghambat yang meliputi faktor internal berupa pembinaan akhlak pada peserta didik hanya dilakukan sebatas di sekolah saja dan belum adanya tindak lanjutnya. Adapun faktor eksternal meliputi lingkungan keluarga, lingkungan masyarakat, dan arus globalisasi modern.

\section{DAFTAR PUSTAKA}

[1] M. Jannah, "PERANAN GURU DALAM PEMBINAAN AKHLAK MULIA PESERTA DIDIK (STUDI KASUS DI MIS DARUL ULUM, MADIN SULAMUL ULUM DAN TPA AZ-ZAHRA DESA PAPUYUAN)," Al-Madrasah: Jurnal Pendidikan Madrasah Ibtidaiyah. Sekolah Tinggi Ilmu Qur an Amuntai, p. 137, 2019.

[2] N. I. Sukoco and N. Nurdin, "Implementasi Pendidikan Karakter Dalam Pembinaan Akhlak Di SMP Unismuh Makassar," Equilibrium: Jurnal Pendidikan, vol. 6, no. 2. 
Publikasi Jurnal Ilmiah Akademik Universitas Muhammadiyah Makassar, pp. 112-118, 2018.

[3] H. Riofita, "BENTUK PERANAN GURU DALAM MEMBERIKAN PENDIDIKAN KEPEMIMPINAN," POTENSIA: Jurnal Kependidikan Islam, vol. 2, no. 1. Universitas Islam Negeri Sultan Syarif Kasim Riau, p. 85, 2016.

[4] K. A. Jasmi, A. H. Tamuri, and M. I. M. Hamzah, "Sifat dan Peranan Keperibadian Guru Cemerlang Pendidikan Islam (GCPI) dan Hubungannya Dengan Motivasi Pelajar," Jurnal Teknologi, vol. 51, no. 1. Penerbit UTM Press, 2009.

[5] J. H. McMillan, Fundamentals of educational research. Pearson, 2015.

[6] S. Arikunto, "Prosedur penelitian." Jakarta: rineka cipta, 2010.

[7] A. Zulianingsih, "STRATEGI DAN PENDEKATAN GURU PENDIDIKAN AGAMA ISLAM DALAM PEMBINAAN KEBERAGAMAAN REMAJA," TA 'DIBUNA: Jurnal Pendidikan Agama Islam, vol. 2, no. 1. Universitas Islam Sultan Agung, p. 71, 2019.

[8] Z. Zulpadli, "Perkembangan TIK, Globalisasi dan Peranan Guru Pendidikan Kewarganegaraan dalam Pengembangan Pendidikan Karakter," Prosiding Seminar Nasional Pendidikan KALUNI, vol. 1. Universitas Indraprasta PGRI, 2018.

[9] F. D. Mukti, "INTEGRASI LITERASI SAINS DAN NILAINILAI AKHLAK DI ERA GLOBALISASI," Abdau: Jurnal Pendidikan Madrasah Ibtidaiyah, vol. 1, no. 1. Sekolah Tinggi Pendidikan Islam (STPI) Bina Insan Mulia Yogyakarta, pp. 318-338, 2018.

[10] Z. Zainuddin, "Pengembangan Buku Ajar Akidah Akhlak untuk Meningkatkan Pemahaman Siswa Madrasah," Jurnal Pendidikan Islam Indonesia, vol. 3, no. 2. LP2M Universitas Ibrahimy, pp. 362-375,
2019.

[11] S. S. Is, "PERANAN GURU PENDIDIKAN AGAMA ISLAM DALAM MEMBIASAKAN SISWA SHALAT BERJAMA'AH," TARBAWI : Jurnal Pendidikan Agama Islam, vol. 2, no. 1. Publikasi Jurnal Ilmiah Akademik Universitas Muhammadiyah Makassar, pp. 3342, 2017.

[12] repositori P. A. I. S. P. Pasuruan, "PERANAN GURU PENDIDIKAN AGAMA ISLAM DALAM PEMBENTUKAN KARAKTER SISWA YANG BERAKHLAKUL KARIMAH DI SDN JATIREJO I LEKOK." Center for Open Science, 2019. 